\title{
Dynamic shifts in corticostriatal expression patterns of the immediate early genes Homer la and Zif268 during early and late phases of instrumental training
}

\author{
Pepe J. Hernandez, ${ }^{1,2,4}$ Craig A. Schiltz, ${ }^{1,3}$ and Ann E. Kelley ${ }^{1,2}$ \\ ${ }^{1}$ University of Wisconsin School of Medicine, Department of Psychiatry, Madison, Wisconsin 53719, USA; ${ }^{2}$ University of Wisconsin \\ School of Medicine, Neuroscience Training Program, Madison, Wisconsin 5371, USA; ${ }^{3}$ University of Wisconsin School of Medicine, \\ Medical Scientist Training Program, Madison, Wisconsin 53719, USA
}

\begin{abstract}
Adaptive motor actions require prior knowledge of instrumental contingencies. With practice, these actions can become highly automatic in nature. However, the molecular and anatomical substrates mediating these related forms of learning are not understood. In the present study, we used in situ hybridization to measure the mRNA levels of two immediate early genes (IEGs) in an instrumental paradigm where rats learned to lever-press for food. We report that after three training sessions, Homer $1 a$ and Zif268 (an effector and regulatory IEG, respectively) were significantly induced within an extensive corticostriatal network relative to untrained controls. With extended training (23 sessions), however, a shift in the expression patterns of the two genes was evident. Expression of Homer la (official symbol Homerl) decreased significantly in frontal and cingulate cortices, whereas striatal expression was generally maintained. Interestingly, Homer la expression markedly increased with extensive training in the ventrolateral region of the striatum (VLS) relative to early learners, suggesting that plasticity in the VLS is required for the efficient production of the learned behavior or in habit formation. Zif268 (official symbol Egrl) expression generally decreased with extensive training; however, these changes were not significant. These results demonstrate for the first time, on a molecular level, a dynamic shift in the contribution of corticostriatal systems mediating the early acquisition and consolidation of goal-directed responses to those engaged after extensive training.
\end{abstract}

With practice, performance of newly learned motor skills gradually improves until responding becomes relatively effortless or automatic in nature (Ungerleider et al. 2002; Doyon and Benali 2005). Such skills are often obtained by instrumental learning and therefore require knowledge of response-outcome contingencies. With extended training, responding is controlled by habit or stimulus-response associations (White 1997; Everitt et al. 2001; Packard and Knowlton 2002). These dynamic and intimately coupled forms of learning are presumably regulated by a multitude of plasticity-related genes. A subset of these genes, the immediate early genes (IEGs), are induced by neural activity and are critical for the type of plasticity involved in memory consolidation (Lanahan and Worley 1998).

The IEGs Homer 1a (official symbol Homer1) and Zif268 (official symbol Egr1) are implicated in various models of synaptic plasticity and learning and memory (de Bartolomeis and Iasevoli 2003; Igaz et al. 2004; Knapska and Kaczmarek 2004). The protein product of the regulatory IEG Zif268 (erg1, NGFI-A, krox24, and ZENK) is a transcription factor that regulates the expression of other learning-related genes (Bozon et al. 2002), where the protein product of the effector gene Homer 1a (Vesl-1S) is known to be targeted to the synapse and interacts directly with other proteins in the postsynaptic density to facilitate changes in synaptic structure and function (Brakeman et al. 1997; Kato et al. 1998). However, no information is available regarding the role of Homer $1 a$ and Zif268 in the brain during the formation of memory for motor skills attained as a result of instrumental learning.

Instrumental learning (lever-pressing for a food reward) is

${ }^{4}$ Corresponding author.

E-mail hernandez@email.chop.edu; fax (215) 898-8780.

Article is online at http://www.learnmem.org/cgi/doi/10.1101//m.335006. known to engage a distributed corticostriatal network and is dependent on dopamine D1, AMPA, NMDA, and metabotropic glutamate receptor (mGLuR) activity (Salamone et al. 2001; Kelley et al. 2003; Hernandez et al. 2005). Indeed, NMDA receptors can drive the expression of Homer 1a (and Zif268) (Cole et al. 1989; Brakeman et al. 1997; Kato et al. 1997), thereby altering the number and activity of mGluRs receptors (Ciruela et al. 1999; Kammermeier et al. 2000; Ango et al. 2001; Minami et al. 2003). In turn, mGluRs modulate NMDA receptor signal transduction (Pisani et al. 2001).

Here, we used in situ hybridization to examine Homer $1 a$ and Zif268 mRNA expression patterns in rats early in learning and after extensive training in a lever-pressing task. We report for the first time that both IEGs were significantly induced throughout an extensive corticostriatal network during early phases of instrumental learning. However, extensive training was accompanied by a significant decrease in the expression of Homer 1a in frontal and cingulate cortices, whereas striatal expression of the gene remained largely unchanged with the exception of a significant increase in the ventrolateral striatum. In contrast, with extensive training, Zif268 tended to decrease throughout the majority of these regions. Thus, these data demonstrate dynamic shifts in gene expression throughout one or more corticostriatal networks that differentially control the initial learning of motor skills and, ultimately, certain aspects of performance such as response automaticity.

\section{Results}

Behavioral data

In order to examine Homer 1a and Zif268 induction over the course of learning, two groups of rats were trained in the lever- 
pressing task to varying extents (Early Learners, EL and Overtrained, OT). Two pseudotrained groups, the Early Learning Controls and Overtrained Controls (ELC and OTC, respectively), were exposed to precisely the same conditions, with the exception that lever-pressing produced no programmed consequences. Figure $1 \mathrm{~A}$ shows that rats in the EL group needed three sessions prior to sacrifice to learn the response-outcome contingency ( 100 lever presses). The OT rats experienced 20 additional sessions in order to assess the effects of extensive training on gene expression. Prior to sacrifice, a repeated-measures ANOVA over sessions 16-23 was conducted to determine whether responding by OT rats had stabilized. Indeed, this analysis revealed no significant improvements in performance during this 8 -d period ( 400 leverpresses per session, $\left.F_{(7,49)}=1.82, P>0.1\right)$. Figure $1 \mathrm{~B}$ depicts the various brain regions selected for the relative quantification of Homer $1 a$ and Zif268 message (this figure also lists abbreviations used for each brain region). These regions were chosen based on their involvement in various models of learning and memory and in goal-directed behaviors.

\section{Patterns of Homer la expression}

Our initial analysis was aimed at determining whether neural processes involved in associative response-outcome learning were sufficient to induce Homer $1 a$ gene expression. Figure $2 \mathrm{~A}$ (top) provides a summary of the effect of $3 \mathrm{~d}$ of training on Homer $1 a$ expression within 13 different brain regions grouped into frontal/cingulate cortices, striatum, and limbic/neocortical regions. Homer $1 a$ expression in the ELC group was highest in the OFC, and sensory and motor cortices (note the different scales of the $y$-axes). Moderate levels of expression were found in the PFC, cingulate (ACC, MCC), DMS, hippocampus, and amygdala, where the lowest levels were detected in the remainder of the striatum (NAc, DS, DLS, PS, VLS). To determine whether early learning processes induced Homer $1 a$ expression, a repeatedmeasures ANOVA was performed on data from the EL and ELC groups. Indeed, this analysis revealed a significant effect of training on Homer $1 a$ expression $\left(F_{(1,12)}=10.96, P=0.006\right)$, as well as a significant training $\times$ brain region interaction $\left(F_{(1,12)}=6.35\right.$, $P<0.0001)$. Given this interaction, we further analyzed potential differences in individual brain regions. Animals in the EL group had significantly higher Homer 1a mRNA levels in the frontal cortex (OFC and PFC), the anterior and middle portions of the cingulate (ACC and MCC), the dorsal medial striatum (DMS), the hippocampus, and sensory and motor cortices relative to the ELC group $(P<0.05)$. Considerable, but nonsignificant increases were observed in the rest of the striatum (NAc, DLS, PS, and VLS). Notably, relative to ELC animals, no decreases in gene expression were found in the EL group in any of the regions examined, nor were any obvious decreases observed in regions not described herein.

To determine the effect of extensive training on Homer $1 a$ expression, we made three additional comparisons. First, we compared overtrained animals with their own controls to account for factors including the number of exposures to the experimental context and the passage of time. Figure 2A (bottom) demonstrates that Homer $1 a$ expression in OT rats was significantly lower than in OTC rats, but only in frontal and cingulate regions. Indeed, in comparing OT and OTC groups, a repeatedmeasures ANOVA indicated a significant training effect and training $\times$ region interaction $\left(F_{(1,11)}=4.70, P=0.05\right.$; $F_{(1,12)}=6.94, P<0.0001$, respectively), a result of differences in expression levels in the OFC, PFC, and ACC $(P<0.05)$ (with a trend toward significance in the MCC, $P=0.08$ ).

Next, we compared the EL and OT groups (Fig. 4, below; white bars) in order to discern differences in gene expression

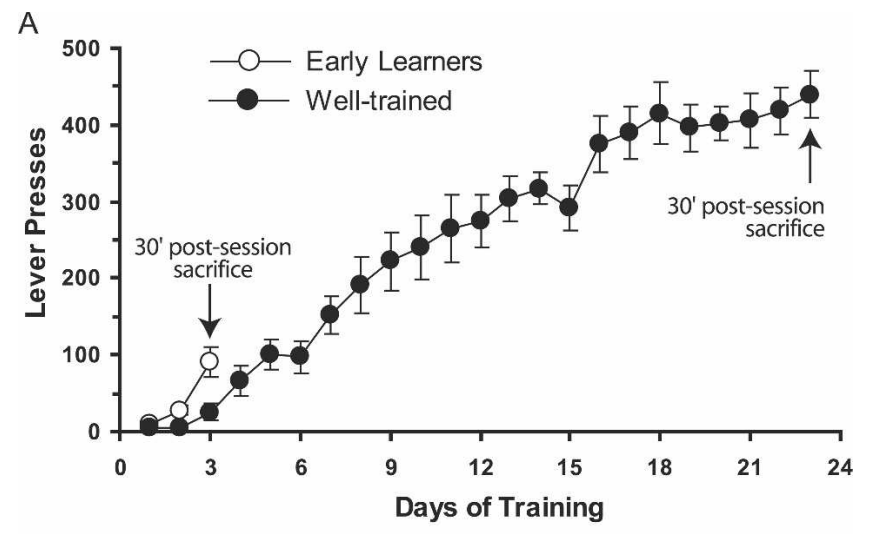

B
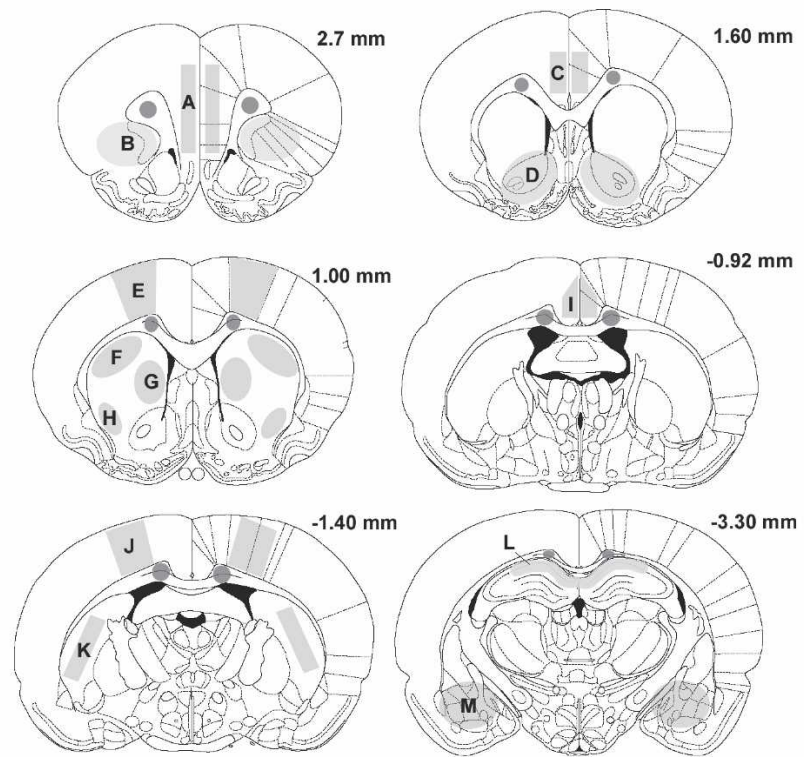

Figure 1. Behavioral assessment of learning in rats used for Homer $1 \mathrm{a}$ and Zif268 in situ hybridization studies. (A) To compare gene expression in the brains of rats at different stages of learning, one group of rats, the Early Learners $(n=8, E L)$, were trained to lever-press for a sugar reward just until they demonstrated evidence of having acquired the responseoutcome association (Day 3). A second group, the Overtrained group $(n=8, \mathrm{OT})$, was trained until asymptotic levels of responding were achieved to ensure all rats had maximized performance (Day 23). Two additional groups, the Early Learning Control ( $n=6$, ELC), and Overtrained Control (OTC, $n=5$ ) groups did not have active levers, and therefore did not learn the task but were sacrificed at the same time point as the EL and OT groups, respectively. All rats were sacrificed $30 \mathrm{~min}$ following the end of their last 15-min session and processed for in situ hybridization. Data represent average number of lever presses \pm SEM. (B) Coronal sections adapted from the atlas of Paxinos and Watson (1998) demonstrating where subsequent measures of Homer $1 a$ and Zif268 signal were obtained. Sections are labeled in millimeters from bregma. Unlabeled shaded regions within the corpus callosum indicate where background measurements were taken. Labeled areas correspond to the following brain regions: $A$, medial prefrontal cortex (PFC); $B$, orbitofrontal cortex (OFC); $C$, anterior cingulate cortex (ACC); $D$, nucleus accumbens (NAc); $\mathrm{E}$, primary motor cortex (Motor $\mathrm{Cx}$ ); $\mathrm{F}$, dorsal lateral striatum (DLS); G, dorsal medial striatum (DMS); H, ventrolateral striatum (VLS); I, middle cingulate cortex (MCC); J, sensory cortex (Sens Cx); K, posterior striatum (PS); L, hippocampus CA1 region (Hippo); M, amygdala (Amy).

between rats engaged in early action-outcome learning versus rats well-trained in the task. Furthermore, this comparison provided a built-in control measure of motor activity due to increased lever-pressing on gene expression. An ANOVA conducted on these data indicated no effect of training, but did reveal a 
A Homer 1a mRNA expression during early and late phases of procedural learning
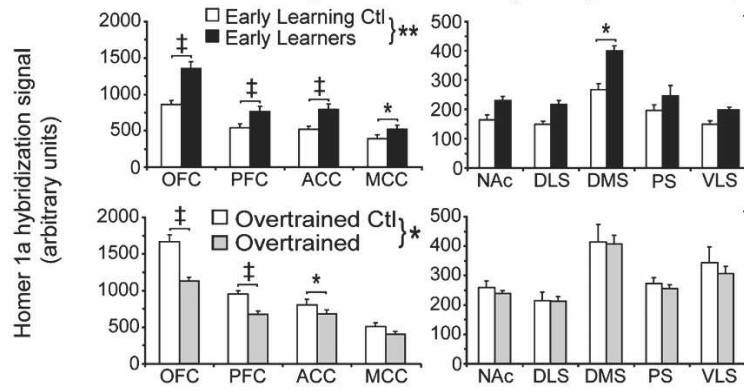

B

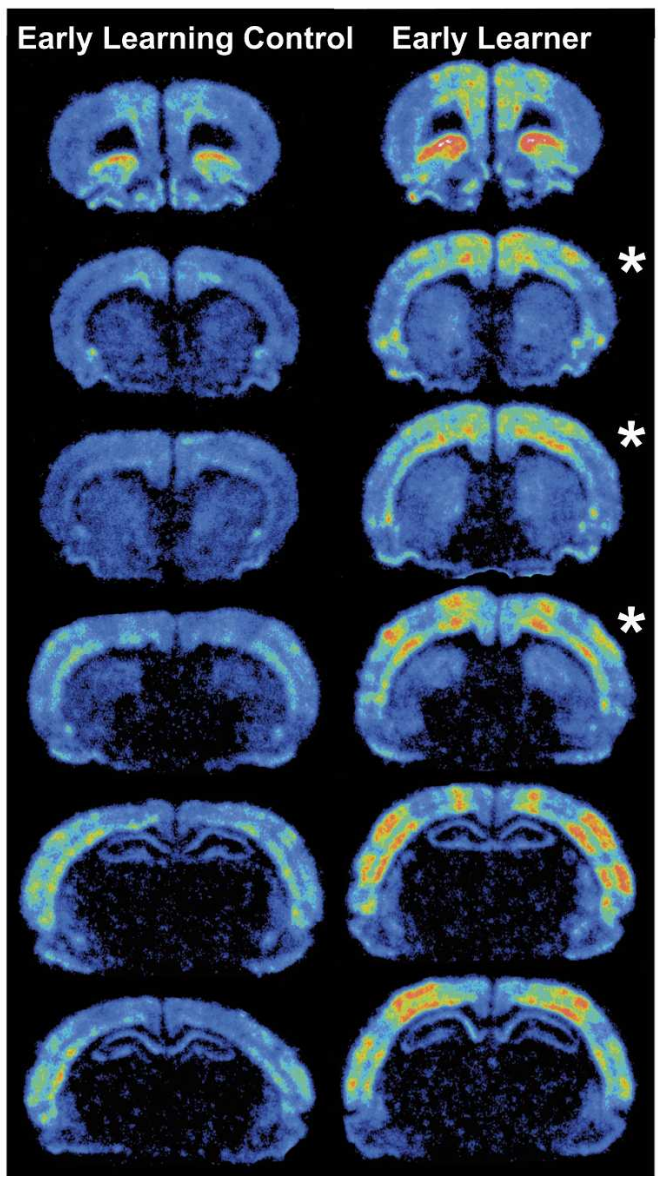

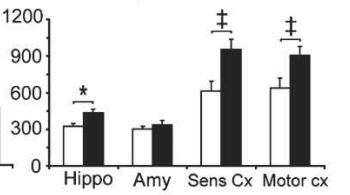

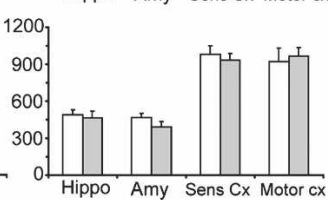

C

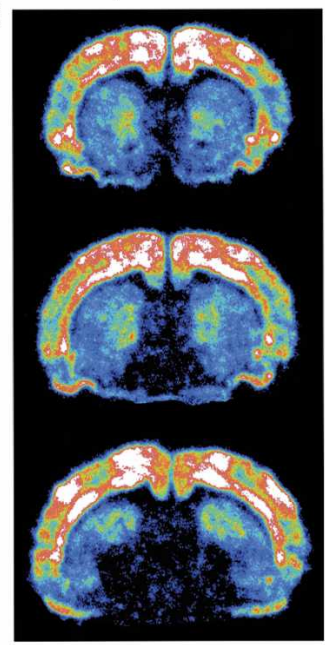

D

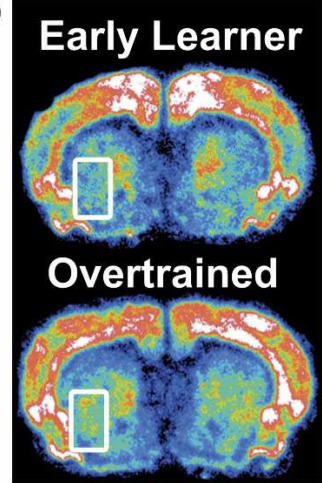

Figure 2. Homer $1 a$ is differentially induced during early and late phases of instrumental learning. $(A)$ A regional analysis of Homer $1 a$ mRNA expression in the brains of (top) Early Learning Controls (ELC, $n=6$, white bars) vs. Early Learners (EL, $n=8$, black bars), and (bottom) Overtrained Controls (OTC, $n=5$, white bars) vs. Overtrained rats (OT, $n=8$, gray bars). Learning the task results in the induction of Homer $1 a$ expression, which is generally maintained as the task becomes well-learned, except within prefrontal regions. Note the increase in expression in the VLS. Data represent mean Homer $1 a$ hybridization signal \pm SEM. A list of regions corresponding to the regional abbreviations on the $x$-axis can be found in the legend to Figure 1 . ${ }^{*} P<0.05,{ }^{*} P<0.01, \dagger P<0.005, \ddagger P<0.0001$. Symbols next to the key represent $P$-values from an overall repeated-measures ANOVA, whereas symbols over pairs of bars represent $P$-values from post hoc tests. Note the different scales used for the $y$-axes. (B) Representative phosphorescence images of coronal sections hybridized with ${ }^{35} \mathrm{~S}$-labeled Homer $1 \mathrm{a}$ antisense riboprobe from which pixel intensity measurements were taken. Sections from the ELC and EL rats proceed from anterior to posterior down the column. (C) Sections with asterisks from $B$ are redisplayed here, but with the signal gain increased to better view the striatal signal. Note the strong signal intensity in the dorsal medial striatum. (D) Sections from representative rats from the EL and OT groups. The rectangles circumscribing the ventrolateral striatum mark the only region in which increased Homer $1 a$ expression was found after the task had been well learned.

training $\times$ region interaction $\left(F_{(1,12)}=3.07, P=0.0006\right)$. Indeed, this interaction was due to significant decreases in Homer 1a expression in OT rats relative to EL rats specifically within the OFC,
PFC, ACC, and MCC $(P<0.05)$, except for an intriguing and significant increase in Homer 1a expression in OT rats in the VLS $(P<0.05)$. In contrast, expression was clearly maintained or unchanged throughout the rest of the striatum. No differences were noted in the hippocampus, amygdala, and sensory and motor cortices, as well. Thus, rats overtrained in the task showed decreased expression of Homer $1 a$ in frontal/cingulate regions relative to OTC rats but, more importantly, relative to EL rats as well, demonstrating differential changes in gene expression across regions over time. Furthermore, given that expression levels decrease or are maintained in most regions in OT rats, it is likely that the initial learning-related induction of Homer $1 a$ observed in the EL group is not due to simple increases in motor activity (leverpressing).

A comparison of expression levels in the two control groups was carried out in order to discern the effect of multiple exposures to the experimental context on Homer $1 a$ expression in the absence of explicit instrumental learning. Interestingly, we found that Homer $1 a$ mRNA levels increased throughout most brain regions in OTC rats relative to ELC rats (cf. control values in Fig. 2A, top and bottom), likely indicating a contextual conditioning effect resulting from multiple pairings between food and the testing environment. Indeed, ANOVA revealed a significant group effect and group $\times$ region interaction $\left(F_{(1,9)}=29.19\right.$, $P=0.0004 ; F_{(1,12)}=11.20, P<0.0001$, respectively). Significant differences were found in all regions except for the NAc, DLS, and PS. Importantly, increased gene expression in controls over time was not paralleled by a similar increase in rats that have been well trained in the task.

Pseudocolored phosphorimages of coronal brain slices taken from representative ELC and EL rats are shown in Figure $2 \mathrm{~B}$. Homer $1 \mathrm{a}$ was expressed within discrete lamina and functional regions of the cortex. Although it cannot be determined exactly, these regions appear to correspond to primary motor, primary somatosensory (barrel field), and secondary somatosensory cortices (Paxinos and Watson 1998). In general, expression visibly increased throughout the brain of early learners, except in the striatum where expression was relatively lower. Therefore, to better view the distribution of Homer 1a mRNA within the striatum, the sections indicated by asterisks are redisplayed in Figure $2 \mathrm{C}$ with the signal gain increased. Here, it can be seen that the expression of Homer $1 a$ in the striatum, although widespread, was particularly enriched in the medial and dorsal medial regions of the striatum. 
Homer 1a expression levels in the VLS after extensive training are displayed in Figure 2D within the areas circumscribed by rectangles. Note the signal gain is again increased in order to better view striatal expression.

\section{Patterns of Zif268 expression}

To determine whether this expression profile was particular to Homer $1 a$, we next analyzed the expression patterns of the transcription factor Zif268 in the same animals. Figure 3A demonstrates that Zif268 mRNA expression is generally much greater than that of Homer $1 a$ (note the different scales of the $y$-axes). Expression in the ELC group (Fig. 3A, top) was highest in the OFC and sensory cortex. Slightly lower levels of Zif268 mRNA were detected in the PFC, motor cortex, and the cingulate (ACC and
MCC). The lowest levels of Zif268 mRNA were observed in the hippocampus, amygdala, and the striatum (DMS $>$ DLS $>$ PS, NAc, VLS). To determine whether $3 \mathrm{~d}$ of training had significantly induced Zif268 expression, a repeated-measures ANOVA was performed on data from the EL and ELC groups. ANOVA revealed a significant effect of training on Zif268 expression $\left(F_{(1,12)}=34.11, P<0.0001\right)$, as well as a significant training $\times$ region interaction $\left(F_{(1,12)}=3.97, P<0.0001\right)$. Animals in the EL group had significantly higher Zif268 mRNA levels in the OFC, PFC, ACC, MCC, DLS, DMS, hippocampus, and sensory and motor cortices relative to the ELC group $(P<0.05)$. Again, considerable, but nonsignificant increases were observed in the NAc, PS, and VLS. No decreases in gene expression from the control to learning condition were identified. It is worth mentioning that both Homer $1 a$ and Zif268 were induced in EL rats to very similar extents relative to their respective controls within each region.

As described above, several comparisons were carried out to determine the effect of extensive training on Zif268 expression (OT vs. OTC, EL vs. OT, and ELC vs. OTC). Fig. 3A (bottom) shows little difference in Zif268 mRNA levels between the overtrained rats and their controls. ANOVA indicated a significant training $\times$ region interaction $\left(F_{(1,12)}=1.95, P=0.03\right)$ due to a significant difference in expression in the sensory cortex $(P=0.0004)$.

To reveal the effects of overtraining on Zif268 gene expression, we then compared the EL and OT groups (Fig. 4, black bars). ANOVA revealed a trend toward an effect; however, this did not reach significance. However, it can be observed from Figure 4 that Zif268 expression tended to decrease somewhat across most regions.

Zif268 expression patterns in control groups, however, paralleled those observed for Homer 1a. Significant increases in Zif268 mRNA levels were found in the OTC group relative to the ELC group (group effect: $F_{(1,9)}=14.57$, $P=0.004$, group $\times$ region interaction: $\left.F_{(1,12)}=2.39, P<0.009\right)$. Increased expression in the PFC, OFC, DLS, VLS, hippocampus, and motor cortex $(P<0.05)$ in the OTC group similarly indicated a contextual conditioning effect due to daily exposure to the experimental context in which food was provided.

Figure 3B shows pseudocolored phosphorimages of coronal brain slices taken from representative ELC and EL rats. Zif268 mRNA expression in the cortex was also laminar, but more widely expressed. Nevertheless, discrete functional regions corresponding to those that also expressed Homer $1 a$ can be observed. Figure 3, C and D, provides examples of prefrontal and striatal regions from representative rats from the OT and OTC groups and the OT and EL groups, respectively. 
Correlations between lever-pressing and gene expression To better understand the relationship between gene expression and instrumental behavior, we next investigated whether the level of Homer 1a or Zif268 mRNA expression covaried with the number of lever-presses made over the course of learning (days 3-23). Due to the significant decreases in gene expression found in the frontal and cingulate cortices and the strong maintenance of gene expression in the striatum, we chose to concentrate our analysis on these regions. Figure 5 shows that expression of both Homer $1 a$ and Zif268 mRNA in the OFC tended to be negatively correlated with lever-pressing $(P=0.09$ and $P=0.04$, respectively) providing further evidence that expression levels cannot be directly associated in all regions with motor activity. Consistent with striatal expression patterns, Homer 1 a mRNA levels were not correlated with lever-presses in the DLS or DMS $(P>0.05)$ but a highly significant positive correlation was found in the VLS $(P=0.004)$. In contrast, Zif268 expression in the striatum was negatively correlated in both dorsal striatal regions $(P<0.05)$, where no correlation was found in the VLS $(P>0.05)$.

\section{Expression patterns in emulsion/ Nissl-stained tissue}

In order to better understand the cellular localization of Homer $1 a$ and Zif268 mRNA expression, slides were dipped in an emulsion and Nissl stained. As an example, Figure 6A shows the accumulation of silver grains over the palely stained nuclei of cells in the DMS of representative rats from each group, consistent with neuronal expression. Furthermore, the degree of silver grain accumulation in each group for either gene was consistent with the results of the in situ analysis described above. Dark field photomicrographs of the sensory cortices of EL rats probed for either Homer $1 a$ or Zif268 are shown in Figure 6B. Here, the laminar expression of both genes is clearly evident where Homer $1 a$ was preferentially expressed in layer VI, whereas Zif268 was also expressed at high levels in layer IV.

\section{Discussion}

The purpose of the present study was to identify and characterize the temporal regulation of different classes of plasticity-related genes involved in early and late phases of instrumental motor learning. In doing so, we used in situ hybridization to probe for Homer $1 a$ and Zif268 mRNA during response-outcome learning and after extensive training (see Table 1 for summary of results). We show, for the first time, that the effector and regulatory genes Homer $1 a$ and Zif268 are induced throughout a distributed corticostriatal network during early and late phases of instrumental training. Second, we demonstrate that the neural circuitry associated with early learning differ significantly from those associated with overtraining. For example, as the task became welllearned, Homer $1 a$ expression was considerably maintained (or increased in the VLS) from levels initiallyinduced by early learning. In contrast, expression in frontal and cingulate regions significantly decreased with extensive training. A third and interesting finding relates to the increase in gene expression between the two control groups over time (likely due to contextual conditioning associated with food), an effect not observed in rats that were overtrained in the task. Together, these data provide valuable insight into the molecular and anatomic basis of the neural plasticity that mediates early response-outcome learning and the development of habits and response automatization.
The induction of IEGs has been described in a variety of learning and memory paradigms (Lanahan and Worley 1998). However, very few have examined IEG expression in motor learning paradigms (see Kleim et al. 1996; Kelly and Deadwyler 2002 , 2003). Indeed, no information is available on the role of Homer $1 a$ or Zif268 in appetitively motivated motor learning. In the present study, untrained animals were included to control for the nonspecific effects of handling, food deprivation, exposure to the learning context, and consumption of food on IEG expression. Thus, the primary difference between the untrained and learning animals is that lever-pressing by untrained controls had no programmed consequences, preventing the formation of the response-outcome association. We show for the first time that Homer $1 a$ and Zif268 are expressed in response to early stages of instrumental learning. It is highly unlikely that this transcriptional response is due simply to motor activity associated with lever-pressing, since overtrained animals generally display decreased gene expression, yet performed hundreds of additional lever presses compared with newly trained rats. Furthermore, gene expression within many regions showed no correlation or was negatively correlated with the degree of lever-pressing. Taken together, we provide strong evidence indicating that Homer $1 a$ and Zif268 are induced in response to early response-outcome learning.

A striking result of this study is exemplified in the selective decrease in gene expression in frontal and cingulate cortical regions with training where no changes or increases in expression were found in the striatum. This is consistent with the notion that prefrontal areas respond to changing environmental contingencies and generate outcome expectancies, especially during early learning (Schoenbaum and Roesch 2005). In addition, rats with OFC lesions fail to acquire discriminative Pavlovian approach behaviors, but are unimpaired when preoperatively trained (Chudasama and Robbins 2003). A decrease in prefrontal expression would, therefore, not be surprising in rats that have been trained to make the same response on a predictable schedule of reinforcement for extended periods of time. Furthermore, human imaging studies, albeit not directly comparable, also demonstrate the involvement of prefrontal regions early in instrumental and other forms of motor learning, but not after the tasks had been learned (Jenkins et al. 1994; Raichle et al. 1994; Jueptner et al. 1997; Duncan and Owen 2000; Doyon et al. 2002). This phenomenon, however, has never before been documented on a molecular level, precluding the ability to draw more direct links to changes in neural plasticity.

Unexpectedly, expression of the plasticity-related gene Homer $1 a$ in the VLS appears to be induced to the largest extent, not in response to early learning, but after the rats had become extremely familiar with the task. This increase from early to
Percent change in mRNA levels from early learning to overtrained condition
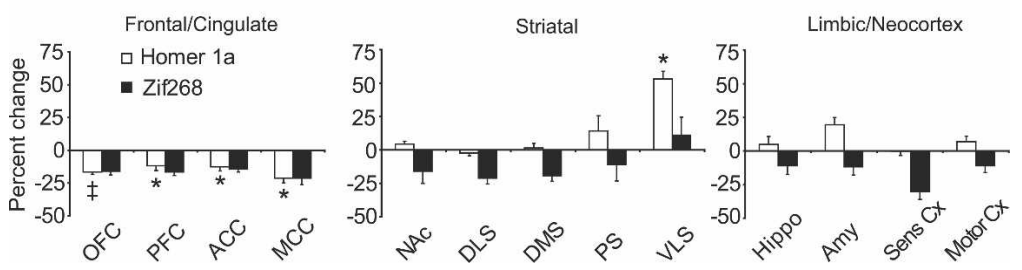

Figure 4. Shifts in Homer $1 a$ expression within prefrontal and striatal regions occurs after extensive training. Overtraining results in the significant decrease in Homer 19 expression in OT rats relative to EL rats in prefrontal regions, whereas expression is generally maintained elsewhere. Zif268 expression generally decreases, although these decreases did not reach significance. Note the significant increase in Homer $1 a$ expression in the VLS. Data represent the mean percent change in hybridization signal \pm SEM from EL to OT conditions for each IEG (Homer 1a, white bars; Zif268, black bars). Symbols above or below bars indicate $P$-values: ${ }^{*} P<0.05,{ }^{*} P<0.01, \dagger P<0.005$, $\ddagger P<0.0001$. 


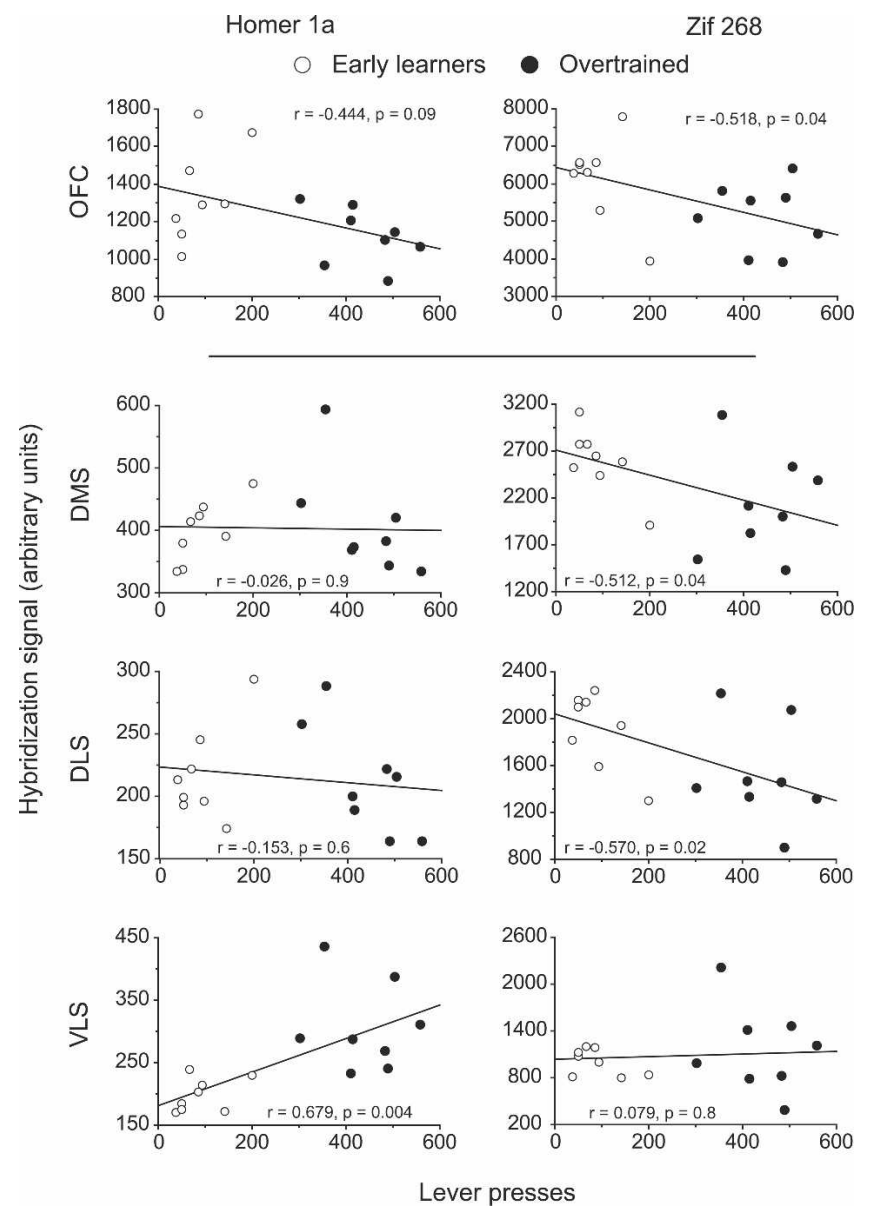

Figure 5. Correlations between Homer $1 a$ or Zif268 expression in prefrontal and striatal regions and instrumental responding. In the orbitofrontal cortex (OFC), where both Homer $1 a$ and Zif268 expression decreased with extensive training, gene expression was negatively correlated with increasing numbers of lever-presses. In the DMS and DLS, Homer $1 a$ was not correlated with lever-pressing behavior (maintained expression), whereas Zif268 expression was negatively correlated. Homer $1 a$ expression in the VLS was the only brain region to be positively correlated with lever-pressing. Lever presses are given on the $x$-axis where the hybridization signal strength in arbitrary units within each region is represented on the $y$-axis. Open and filled circles represent values from individual rats from the Early Learning and Overtrained groups, respectively. Correlations were calculated taking into account the performance of all animals regardless of group. Regression lines are shown in black.

late phases of learning was not observed in any other brain regions analyzed, although we do not rule out the involvement of other regions. In the rat, the lateral striatum receives input from sensory and motor cortices, as well as from the OFC (Beckstead 1979; McGeorge and Faull 1989; Heimer et al. 1995), and controls skilled movements involving the forepaws and orofacial region (Fricker et al. 1996; Cousins et al. 1999). Thus, we hypothesize that the marked increase in Homer 1a expression (and Zif268 to a lesser degree) in the VLS after extensive training could reflect plasticity-related mechanisms that mediate, in part, the refinement of motor skills involved in performance automatization or the efficiency with which the task is performed. Notably, a recent fMRI study revealed that the ventrolateral putamen in human subjects was activated only after performance of a nonrewarded bimanual motor task that was well-practiced and highly automatic in nature (Puttemans et al. 2005). Another recent study found that c-Jun immunoreactivity was elevated in the VLS (referred to as the posterioventral region of the dorsolat- eral striatum) of rats trained in a cued water maze task, which is often used to study habit learning (Teather et al. 2005). Thus, we may have identified an important region of the ventral striatum that participates in the performance of motor programs that are needed in the development of stimulus-response associations or are under their control, or both.

A related finding stems from the observation that Homer $1 a$ and Zif268 expression was particularly enriched in the dorsal medial striatum in both early and late phases of learning (note the pattern in Fig. 2C,D as well as Fig. 3B-D). This area receives extensive projections from both medial prefrontal and cingulate cortices (Beckstead 1979), and may represent yet another component of corticostriatal circuitry that participates in instrumental learning processes. In any case, the fact that this region is highly activated in the EL group suggests that dorsal aspects of striatum are not only involved in S-R or habit learning, but may also mediate early response-outcome learning.

Given the number of published reports pertaining to the involvement of the DLS in habit learning (White 1997; Packard and Knowlton 2002), it is interesting that we did not observe levels of gene expression on the scale of that observed in the VLS. However, it does not imply that an increase in gene expression after extensive training in the VLS is more important for the lever-pressing behavior or even that the VLS contributes to the same aspects of habit learning or the expression of motor responses as does the DLS. Indeed, the lack of major changes in gene expression in the DLS over time does not rule out the possibility that important plasticity-associated events are occurring there. Considering the role of the DLS in habit learning, it may be that the maintenance of Homer $1 a$ in the DLS is important for habit memory. The lack of a positive or negative correlation of lever presses with mRNA levels in the DLS only demonstrates

Table 1. Summary of changes in Homer $1 a$ and Zif268 expression upon learning

\begin{tabular}{|c|c|c|c|c|}
\hline Gene & Region & $\begin{array}{l}\text { Induced by } \\
\text { early } \\
\text { learning }\end{array}$ & $\begin{array}{c}\text { Direction } \\
\text { of change } \\
\text { upon } \\
\text { overtraining }\end{array}$ & $\begin{array}{l}\text { Correlation of } \\
\text { expression with } \\
\text { lever pressing }^{a}\end{array}$ \\
\hline Homer $1 a$ & $\begin{array}{l}\text { OFC } \\
\text { PFC } \\
\text { ACC } \\
\text { MCC } \\
\text { NAC } \\
\text { DLS } \\
\text { DMS } \\
\text { PS } \\
\text { VLS } \\
\text { Hippo } \\
\text { Amy } \\
\text { Sens Cx } \\
\text { Motor Cx }\end{array}$ & $\begin{array}{l}\text { yes } \\
\text { yes } \\
\text { yes } \\
\text { yes } \\
\text { slight } \\
\text { slight } \\
\text { yes } \\
\text { slight } \\
\text { slight } \\
\text { yes } \\
\text { no } \\
\text { yes } \\
\text { yes }\end{array}$ & $\begin{array}{l}\text { down } \\
\text { down } \\
\text { down } \\
\text { down } \\
N C \\
N C \\
N C \\
\text { up } \\
\text { up } \\
\text { NC } \\
\text { up } \\
N C \\
N C\end{array}$ & $\begin{array}{l}\text { negative tendency } \\
\text { none } \\
\text { none } \\
\text { none } \\
\text { none } \\
\text { none } \\
\text { none } \\
\text { none } \\
\text { positive } \\
\text { none } \\
\text { none } \\
\text { none } \\
\text { none }\end{array}$ \\
\hline Zif268 & $\begin{array}{l}\text { OFC } \\
\text { PFC } \\
\text { ACC } \\
\text { MCC } \\
\text { NAC } \\
\text { DLS } \\
\text { DMS } \\
\text { PS } \\
\text { VLS } \\
\text { Hippo } \\
\text { Amy } \\
\text { Sens Cx } \\
\text { Motor Cx }\end{array}$ & $\begin{array}{l}\text { yes } \\
\text { yes } \\
\text { yes } \\
\text { yes } \\
\text { yes } \\
\text { yes } \\
\text { yes } \\
\text { slight } \\
\text { slight } \\
\text { yes } \\
\text { no } \\
\text { yes } \\
\text { yes }\end{array}$ & $\begin{array}{l}\text { down } \\
\text { down } \\
\text { down } \\
\text { down } \\
\text { down } \\
\text { down } \\
\text { down } \\
\text { down } \\
\text { up } \\
\text { down } \\
\text { down } \\
\text { down } \\
\text { down }\end{array}$ & $\begin{array}{l}\text { negative } \\
\text { negative } \\
\text { negative tendency } \\
\text { negative } \\
\text { none } \\
\text { negative } \\
\text { negative } \\
\text { none } \\
\text { none } \\
\text { none } \\
\text { negative } \\
\text { none } \\
\text { none }\end{array}$ \\
\hline
\end{tabular}

Boldface relects significance of $P<0.05$.

${ }^{a}$ Correlations calculated from lever-presses made over days 3-23. 
that Homer $1 a$ expression is maintained; it tells nothing of the importance of gene expression in the DLS relative to other regions. Of course, it is possible that the expression of other genes not examined here may change considerably over time within the DLS.

Unexpectedly, Homer $1 a$ and Zif268 did not appear to be induced in early learners relative to controls within the amygdala, which is known for its functions in both appetitive and aversive forms of Pavlovian (stimulus-stimulus) learning (O'Doherty 2004; Fanselow and Poulos 2005). It is possible that all animals, including controls, formed Pavlovian associations between the experimental context and the sugar reward during habituation to the operant chambers, thereby masking other learning-related inductions. Although we did not find an induction, it should be noted that Zif268 has been shown to play a role in amygdala-mediated learning and memory (de Bartolomeis and Iasevoli 2003; Lee et al. 2005).

An additional finding relates to the increase in both species of mRNA in day 23 controls (OTC group). This increase very likely indicates a transcriptional response mediating food-related conditioning to the experimental context over time. Similar findings have been reported to occur as a result of conditioning to cues related to both food and drugs of abuse (Schroeder et al. 2001, 2003; Holland and Petrovich 2005; Schiltz et al. 2005). Interestingly, while a certain degree of conditioning might also be expected in OT animals, we observed a decrease or only small changes in gene expression across most regions. It may be possible that conditioning is impaired in rats focused on an instrumental task (OT group). However, mRNA levels observed in OT rats likely also reflect the increase in expression due to conditioning. As such, the fact that we observed an actual decrease in prefrontal expression in OT rats, not only relative to overtrained controls, but also relative to early learners (that presumably have not undergone much conditioning), provides powerful support for our initial interpretation that striatal systems tend to control well-learned overt behaviors and perhaps compete for that control with other systems that may be dominant at earlier stages of learning.

Both Homer $1 a$ and Zif268 have been shown in various models of plasticity (both in vivo and in vitro) to help orchestrate the type of synaptic plasticity thought to mediate learning and memory (Davis et al. 2003; Duncan et al. 2005). Previously, it has been demonstrated that instrumental learning is accomplished by a distributed corticostriatal network through the coincident detection of glutamatergic and dopaminergic signals (Smith-Roe and Kelley 2000; Baldwin et al. 2002; Balleine et al. 2003; Dalley et al. 2005; Hernandez et al. 2005). Since Homer 1a codes for a scaffolding protein in the postsynaptic density and modulates glutamate receptor function (Xiao et al. 1998), we hypothesized this gene to be involved in instrumental learning. Similarly, we hypothesized that Zif268 expression, also shown to depend on NMDA receptor activity (Cole et al. 1989), would also be important in this form of memory. Indeed, we have provided evidence that both genes are induced by early learning events but with extensive training, shifts in these expression patterns are evident. Thus, these data address learning-related neural changes over relatively long periods of time on both a systems and molecular level. We believe such approaches are critical in understanding the interaction between genes and behavior. Furthermore, corticostriatal shifts in gene expression may have important implications in drug addiction as drugs of abuse affect both Homer $1 a$ and Zif268 expression in the very same circuitry studied here (Nestler 2001; Swanson et al. 2001; Thomas et al. 2003).

\section{Materials and Methods}

\section{Animals}

A total of 27 male Sprague-Dawley rats (300-325 g) (Harlan Sprague Dawley) were housed in groups of two on a 12-h light/ 12-h dark cycle. To minimize stress and decrease baseline IEG expression, all rats were handled extensively $(\sim 2 \mathrm{wk})$ prior to behavioral procedures. Rats were food deprived and maintained at $90 \%$ of their free-feeding pre-surgical weight. Animal care was in accordance with University of Wisconsin-Madison Animal Care and Use guidelines and the NIH Guide.

\section{Apparatus}

Operant chambers (Coulbourn Instruments) equipped with a retractable lever, a house light, and a food magazine with a light and photosensors were used in all experiments. Data acquisition was controlled by micro-computer (Lablinc, Coulbourn Instruments).

\section{Experimental groups and procedures Instrumental training}

Animals were divided into four groups as follows: Early Learners $(E L, n=8)$, Early Learning Controls (ELC, $n=6)$, Overtrained

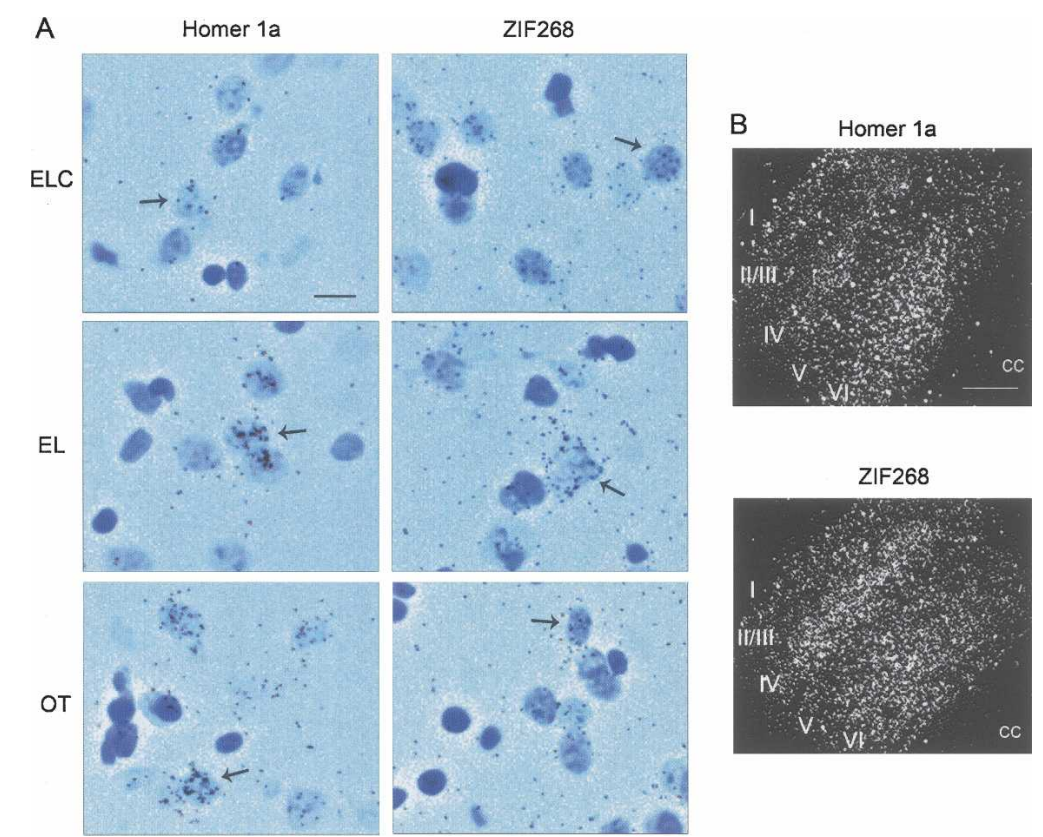

Figure 6. Emulsion autoradiography and Nissl-staining of sections hybridized with ${ }^{35}$ S-labeled Homer $1 a$ or Zif268 antisense probes. (A) Silver grains in the dorsal medial striatum accumulated preferentially over cells with lightly stained, large nuclei (denoted by arrows) in Early Learning Controls (ELC), Early Learners (EL), and Overtrained (OT) rats. The degree of silver grain accumulation is consistent with the results of the in situ hybridization analysis shown in Figures 2 and 3 and with neuronal localization of induced Homer $1 a$ and Zif268 (scale bar, $20 \mu \mathrm{m}$ ). (B) Dark field photomicrographs of the sensory cortex of representative EL rats. Zif268 expression is particularly prominent in layers IV and $\mathrm{VI}$, whereas Homer $1 a$ is preferentially expressed in layer VI. This laminar pattern of expression was evident in most neocortical areas observed (cc; corpus callosum; scale bar, $500 \mu \mathrm{m}$ ). 
(OT, $n=8$ ), and Overtrained Controls (OTC, $n=5$ ). All animals were transported, handled, weighed, and fed in the same fashion at the same time every day $\sim 2$ wk prior to the beginning of all behavioral procedures in order to decrease baseline IEG expression. During this time, the animals' weights were reduced to $90 \%$ of their free-feeding values and sugar pellets were added to the home cage on a daily basis. Prior to testing, all rats were habituated to the operant chambers for $5 \mathrm{~d}$ (15 min each day) with sugar pellets (45 mg, BioServe) placed noncontingently into the food magazine. During the first 15 min instrumental training session, sugar was delivered to EL and OT rats automatically on a random time (RT) 30-sec schedule superimposed upon on a fixed ratio (FR) 1 schedule, such that every lever press was rewarded with one sugar pellet. The RT schedule was included because we found that it facilitates early learning (unpublished findings). During the following daily 15-min sessions, the first 50 lever presses were reinforced on a FR-1 schedule, switching to a variable ratio (VR) 2 schedule thereafter, such that, on average, two lever presses were required to produce a reinforcer. Reinforced lever presses and noncontingent delivery of sugar resulted in the simultaneous onset of the food magazine light $(\sim 0.1 \mathrm{sec}$ in duration). In order to control for sugar consumption in the operant chamber, the average amount of sugar pellets consumed by EL and OT rats after each session was calculated and the same amount supplied noncontingently in the food magazine to the ELC and OTC groups (after ELC and EL groups were sacrificed, the average values from the OT group were used to calculate sugar amounts for the OTC group). ELC and OTC rats also had access to a lever, but pressing resulted in no programmed consequences. The number of training sessions experienced by EL and ELC rats (three in this case) depended on the length of time needed for the EL animals to lever-press at levels significantly above chance. Typically, well-trained rats lever-press $\sim 400$ times per session under this training schedule. Thus, we conservatively estimate early learning to have occurred once lever-pressing reaches $25 \%$ of this value. OT and OTC animals were given 20 additional training sessions to be sure the performance of the task was overtrained in the OT group.

\section{Tissue collection}

Pilot experiments demonstrated that during the course of learning, Homer $1 a$ and Zif268 mRNA levels were induced to the same respective levels when measured at either 30 or 60 min posttraining (data not shown). Therefore, in the present study, rats were anesthetized with halothane and decapitated $30 \mathrm{~min}$ following sessions 3 (ELC and EL groups) or 23 (OTC and OT groups). The heads were cooled for $30 \mathrm{sec}$ in $-70^{\circ} \mathrm{C}$ isopentane. Brains were then rapidly dissected from the cooled heads and kept at $-80^{\circ} \mathrm{C}$ until they were sectioned at $20 \mu \mathrm{m}$ and thaw mounted onto Superfrost slides (Fischer Scientific), warmed at $57^{\circ} \mathrm{C}$ for $1 \mathrm{~min}$, and stored at $-80^{\circ} \mathrm{C}$ until processed for in situ hybridization. Although mRNA levels may not correlate exactly to protein function in vivo, a measure of such still provides useful information regarding the neural response to learningrelated events.

\section{In situ hybridization}

Slides for all groups were processed for in situ hybridization at the same time using the same reagents and conditions to reduce variability. Sections on slides were fixed in $4 \%$ paraformaldehyde in PBS for $2 \mathrm{~h}$ at $4^{\circ} \mathrm{C}$ and then washed three times for $5 \mathrm{~min}$ in $2 \times$ SSC. Slides were incubated in $0.2 \mu \mathrm{g} / \mathrm{mL}$ Proteinase K (Qiagen) in $0.1 \mathrm{M}$ Tris base and $50 \mathrm{mM}$ EDTA (pH 8.1) for $10 \mathrm{~min}$ at $37^{\circ} \mathrm{C}$ and washed in $2 \times$ SSC at room temperature for $2 \mathrm{~min}$. Next, slides were incubated in $0.1 \mathrm{M}$ TEA at room temperature with rapid stirring, and acetic anhydride was added to a final concentration of $0.25 \%(\mathrm{v} / \mathrm{v})$ with rapid stirring for $10 \mathrm{~min}$. Slides were then washed in $2 \times$ SSC for $5 \mathrm{~min}$. Finally, sections were dehydrated in an ascending ethanol series and air dried for $15 \mathrm{~min}$.

Templates for riboprobes were amplified from a rat brain cDNA library. The following primers were used to generate the templates using standard PCR conditions: Homer 1a (GenBank Accession U92079), forward primer 5'-TTCCGAGAGTTCAGAG
CACA-3'(5473-5492), reverse primer 5'-CAGAGATGCATAATAC GACTCACTATAGGGAGATCATACAGCGAAGATCAACGA 3'(5742-5762); Zif268 (GenBank Accession NM_012551), forward primer 5'-CGGGTCTTTCAGACATGACAGC-3' (18391860), reverse primer 5'-CAGAGATGCATAATACGACTCACTA TAGGGAGACCTCATCGTGCTCTAAAGCCTC-3'(2768-2789). Numbers in parentheses after the primer sequence represent the base number as defined by the gene sequence in the UniGene database. Underlined sequence represents the T7 promotor and anchor sequence. An in vitro transcription reaction using amplified template was used to generate ${ }^{35}$ S-labeled Homer 1a or Zif268 antisense or sense probe. The in vitro transcription was carried out in $1 \times$ Transcription Optimized Buffer, $10 \mathrm{mM}$ DTT, $1 \mathrm{U} / \mu \mathrm{L}$ RNasin, $0.375 \mathrm{mM}$ ATP, CTP, GTP, $1 \mathrm{U} / \mu \mathrm{L}$ T7 RNA polymerase (all Promega), $3.5 \mu \mathrm{Ci} / \mu \mathrm{L}\left[\alpha_{-}{ }^{35} \mathrm{~S}\right] \mathrm{UTP}$ (PerkinElmer), and $100 \mathrm{ng}$ template DNA and incubated for $2 \mathrm{~h}$ at $37^{\circ} \mathrm{C}$. RQ1 RNase free DNase (Promega) was added at a concentration of $0.15 \mathrm{U} / \mathrm{mL}$ and incubated for an additional $15 \mathrm{~min}$ at $37^{\circ} \mathrm{C}$. The labeled probes were purified using ProbeQuant G-50 Micro columns (Amersham Biosciences). Radioactivity of labeled probe was determined via scintillation counting and riboprobe was diluted in hybridization solution $(3 \times$ SSC, $10 \%$ dextran sulphate, $1 \times$ Denhardt's solution, $0.2 \mathrm{mg} / \mathrm{mL}$ tRNA, $50 \mathrm{mM} \mathrm{NaPO}_{4}$ buffer, and freshly added DTT to a final concentration of $50 \mathrm{mM}$ ) to $10^{6}$ c.p.m./100 $\mu \mathrm{L}$. One hundred microlitres of the hybridization solution at $55^{\circ} \mathrm{C}$ with labeled probe was applied to each slide. Slides were then coverslipped and incubated at $55^{\circ} \mathrm{C}$ in a hybridization chamber saturated with $75 \%$ formamide for $16 \mathrm{~h}$.

After hybridization, coverslips were removed and slides were washed in $2 \times$ SSC with $2 \mathrm{mM}$ DTT at room temperature for 10 $\mathrm{min}$, three times. Slides were incubated in $1.5 \mathrm{U} / \mathrm{mL}$ RNase A (Qiagen) in RNase buffer $(10 \mathrm{mM}$ Tris/ $\mathrm{HCl}$ and $0.5 \mathrm{M} \mathrm{NaCl}$ at $\mathrm{pH}$ 8.0) at $37^{\circ} \mathrm{C}$ for $1 \mathrm{~h}$, followed by washes in $1 \times$ SSC with $1 \mathrm{mM}$ DTT at room temperature for $5 \mathrm{~min}, 0.5 \times$ SSC with $1 \mathrm{mM}$ DTT at room temperature for $5 \mathrm{~min}$, and $0.1 \times$ SSC with $2 \mathrm{mM}$ DTT at $70^{\circ} \mathrm{C}$ for $1 \mathrm{~h}$. The sections were then dehydrated in an ascending series of ethanol and air-dried. Sections were exposed to a PhosphorImager screen for $2 \mathrm{wk}$. Screens were scanned on a Typhoon 9410 PhosphorImager (Amersham Biosciences) for later quantification. Slides were then covered with NTB2 emulsion (Eastman Kodak Co.) and exposed for 2 mo for analysis of silver grain distribution. After development, slides were counterstained with Nissl stain and dehydrated through a graded series of ethanol and xylene. A coverslip was then applied. Images were taken with a Leica DC 300F digital camera linked to Image Pro-Plus software on a PC through a Leica DMRX microscope.

\section{Data and statistical analysis}

Phosphorescence data obtained from the Homer 1a and Zif268 in situ hybridization experiments were quantified using ImageQuant software and the quantification of signal in particular brain regions was performed using ImageQuant software. Importantly, because of the large number of slides used in the experiment, two PhosphorImager screens were needed. Both screens were purchased new for this experiment to minimize variability. Nevertheless, half of the slides from each experimental group were run on each screen to counterbalance any differences in signal detection between the two screens. Hybridization signals from each hemisphere were averaged together in order to arrive at a single value for each particular brain region from which the average background readings from that particular section (taken from corpus callosum) were subtracted (see Fig. 1). No observable signal was detected using sense probes (data not shown). The regions analyzed were chosen based on their involvement in learning and memory. We focused the active search within these specified regions; however, the analysis performed does not preclude the involvement of other brain regions. Additionally, although regions such as the nucleus accumbens and amygdala are composed of several distinct subregions, precise distinctions between these subregions were not clear enough in the tissues; thus we analyzed the accumbens and amygdala each as a whole. Importantly, adjacent 20 - $\mu \mathrm{m}$ sections were chosen to probe for Homer $1 a$ and Zif268 mRNA such that accurate comparisons be- 
tween expression levels could be made. Resultant data were analyzed by performing a repeated-measures ANOVA followed by analysis of simple main effects for interactions. Training experience or group was the between-subjects factor and gene expression within each brain region was repeated-measures factor. ANOVAs were carried out on individual brain regions if significant interactions from the overall ANOVA were found. Significance was set at $P<0.05$.

For qualitative analysis of emulsion autoradiography, images were captured at a magnification of $5 \times$ for dark field images of the sensory cortex and $40 \times$ for bright field images of the dorsal medial striatum. Regions photographed correspond to those depicted in Figure 1B. All images were processed using Adobe Photoshop.

\section{Acknowledgments}

This work was supported by NIDA grant DA04788. Additionally, we thank Dr. Charles Landry, Quentin Bremer, Curtis Ryals, and Emily Baum for their technical support.

\section{References}

Ango, F., Prezeau, L., Muller, T., Tu, J.C., Xiao, B., Worley, P.F., Pin, J.P., Bockaert, J., and Fagni, L. 2001. Agonist-independent activation of metabotropic glutamate receptors by the intracellular protein Homer. Nature 411: 962-965.

Baldwin, A.E., Sadeghian, K., and Kelley, A.E. 2002. Appetitive instrumental learning requires coincident activation of NMDA and dopamine D1 receptors within the medial prefrontal cortex. $J$. Neurosci. 22: 1063-1071.

Balleine, B.W., Killcross, A.S., and Dickinson, A. 2003. The effect of lesions of the basolateral amygdala on instrumental conditioning. $J$. Neurosci. 23: 666-675.

Beckstead, R.M. 1979. An autoradiographic examination of corticocortical and subcortical projections of the mediodorsal-projection (prefrontal) cortex in rats. J. Comp. Neurol. 84: $43-62$.

Bozon, B., Davis, S., and Laroche, S. 2002. Regulated transcription of the immediate-early gene Zif268: Mechanisms and gene dosage-dependent function in synaptic plasticity and memory formation. Hippocampus 12: 570-577.

Brakeman, P.R., Lanahan, A.A., O'Brien, R., Roche, K., Barnes, C.A., Huganir, R.L., and Worley, P.F. 1997. Homer: A protein that selectively binds metabotropic glutamate receptors. Nature 386: $284-288$

Chudasama, Y. and Robbins, T.W. 2003. Dissociable contributions of the orbitofrontal and infralimbic cortex to Pavlovian autoshaping and discrimination reversal learning: Further evidence for the functional heterogeneity of the rodent frontal cortex. J. Neurosci. 23: $8771-8780$.

Ciruela, F., Soloviev, M.M., and McIlhinney, R.A. 1999. Co-expression of metabotropic glutamate receptor type $1 \alpha$ with Homer-1a/Vesl-1S increases the cell surface expression of the receptor. Biochem. J. 341: 795-803.

Cole, A.J., Saffen, D.W., Baraban, J.M., and Worley, P.F. 1989. Rapid increase of an immediate early gene messenger RNA in hippocampal neurons by synaptic NMDA receptor activation. Nature 340: 474-476.

Cousins, M.S., Trevitt, J., Atherton, A., and Salamone, J.D. 1999. Different behavioral functions of dopamine in the nucleus accumbens and ventrolateral striatum: A microdialysis and behavioral investigation. Neuroscience 91: 925-934.

Dalley, J.W., Laane, K., Theobald, D.E., Armstrong, H.C., Corlett, P.R., Chudasama, Y., and Robbins, T.W. 2005. Time-limited modulation of appetitive Pavlovian memory by D1 and NMDA receptors in the nucleus accumbens. Proc. Natl. Acad. Sci. 102: 6189-6194.

Davis, S., Bozon, B., and Laroche, S. 2003. How necessary is the activation of the immediate early gene Zif268 in synaptic plasticity and learning? Behav. Brain Res. 142: 17-30.

de Bartolomeis, A. and Iasevoli, F. 2003. The Homer family and the signal transduction system at glutamatergic postsynaptic density: Potential role in behavior and pharmacotherapy. Psychopharmacol. Bull. 37: 51-83.

Doyon, J. and Benali, H. 2005. Reorganization and plasticity in the adult brain during learning of motor skills. Curr. Opin. Neurobiol. 15: $161-167$

Doyon, J., Song, A.W., Karni, A., Lalonde, F., Adams, M.M., and Ungerleider, L.G. 2002. Experience-dependent changes in cerebellar contributions to motor sequence learning. Proc. Natl. Acad. Sci.
99: 1017-1022.

Duncan, J. and Owen, A.M. 2000. Common regions of the human frontal lobe recruited by diverse cognitive demands. Trends Neurosci. 23: $475-483$.

Duncan, R.S., Hwang, S.Y., and Koulen, P. 2005. Effects of Vesl/Homer proteins on intracellular signaling. Exp. Biol. Med. (Maywood) 230: $527-535$.

Everitt, B.J., Dickinson, A., and Robbins, T.W. 2001. The neuropsychological basis of addictive behaviour. Brain Res. Brain Res. Rev. 36: 129-138.

Fanselow, M.S. and Poulos, A.M. 2005. The neuroscience of mammalian associative learning. Annu. Rev. Psychol. 56: 207-234.

Fricker, R.A., Annett, L.E., Torres, E.M., and Dunnett, S.B. 1996. The placement of a striatal ibotenic acid lesion affects skilled forelimb use and the direction of drug-induced rotation. Brain Res. Bull. 41: $409-416$.

Heimer, L., Zahm, D.S., and Alheid, G.F. 1995. Basal ganglia. In The rat nervous system. (ed. P. G) pp. 579-628, Academic Press, San Diego, CA

Hernandez, P.J., Andrzejewski, M.E., Sadeghian, K., Panksepp, J.B., and Kelley, A.E. 2005. AMPA/kainate, NMDA, and dopamine D1 receptor function in the nucleus accumbens core: A context-limited role in the encoding and consolidation of instrumental memory. Learn. Mem. 12: 285-295.

Holland, P.C. and Petrovich, G.D. 2005. A neural systems analysis of the potentiation of feeding by conditioned stimuli. Physiol. Behav. 86: 747-761.

Igaz, L.M., Bekinschtein, P., Izquierdo, I., and Medina, J.H. 2004. One-trial aversive learning induces late changes in hippocampal CaMKII $\alpha$, Homer 1a, Syntaxin 1a and ERK2 protein levels. Brain Res. Mol. Brain Res. 132: 1-12.

Jenkins, I.H., Brooks, D.J., Nixon, P.D., Frackowiak, R.S., and Passingham, R.E. 1994. Motor sequence learning: A study with positron emission tomography. J. Neurosci. 14: 3775-3790.

Jueptner, M., Stephan, K.M., Frith, C.D., Brooks, D.J., Frackowiak, R.S., and Passingham, R.E. 1997. Anatomy of motor learning. I. Frontal cortex and attention to action. J. Neurophysiol. 77: 1313-1324.

Kammermeier, P.J., Xiao, B., Tu, J.C., Worley, P.F., and Ikeda, S.R. 2000. Homer proteins regulate coupling of group I metabotropic glutamate receptors to $\mathrm{N}$-type calcium and M-type potassium channels. J. Neurosci. 20: 7238-7245.

Kato, A., Ozawa, F., Saitoh, Y., Hirai, K., and Inokuchi, K. 1997. vesl, a gene encoding VASP/Ena family related protein, is upregulated during seizure, long-term potentiation and synaptogenesis. FEBS Lett. 412: 183-189.

Kato, A., Ozawa, F., Saitoh, Y., Fukazawa, Y., Sugiyama, H., and Inokuchi, K. 1998. Novel members of the Vesl/Homer family of PDZ proteins that bind metabotropic glutamate receptors. J. Biol. Chem. 273: 23969-23975.

Kelley, A.E., Andrzejewski, M.E., Baldwin, A.E., Hernandez, P.J., and Pratt, W.E. 2003. Glutamate-mediated plasticity in corticostriatal networks: Role in adaptive motor learning. Ann. N. Y. Acad. Sci. 1003: $159-168$.

Kelly, M.P. and Deadwyler, S.A. 2002. Acquisition of a novel behavior induces higher levels of Arc mRNA than does overtrained performance. Neuroscience 110: 617-626.

. 2003. Experience-dependent regulation of the immediate-early gene arc differs across brain regions. J. Neurosci. 23: 6443-6451.

Kleim, J.A., Lussnig, E., Schwarz, E.R., Comery, T.A., and Greenough, W.T. 1996. Synaptogenesis and Fos expression in the motor cortex of the adult rat after motor skill learning. J. Neurosci. 16: 4529-4535.

Knapska, E. and Kaczmarek, L. 2004. A gene for neuronal plasticity in the mammalian brain: Zif268/Egr-1/NGFI-A/Krox-24/TIS8/ZENK? Prog. Neurobiol. 74: 183-211.

Lanahan, A. and Worley, P. 1998. Immediate-early genes and synaptic function. Neurobiol. Learn. Mem. 70: 37-43.

Lee, J.L., Di Ciano, P., Thomas, K.L., and Everitt, B.J. 2005. Disrupting reconsolidation of drug memories reduces cocaine-seeking behavior. Neuron 47: 795-801.

McGeorge, A.J. and Faull, R.L.M. 1989. The organization of the projection from the cerebral cortex to the striatum in the rat. Neuroscience 29: 503-537.

Minami, I., Kengaku, M., Smitt, P.S., Shigemoto, R., and Hirano, T. 2003. Long-term potentiation of mGluR1 activity by depolarization-induced Homer1a in mouse cerebellar Purkinje neurons. Eur. J. Neurosci. 17: 1023-1032.

Nestler, E.J. 2001. Molecular basis of long-term plasticity underlying addiction. Nat. Rev. Neurosci. 2: 119-128.

O'Doherty, J.P. 2004. Reward representations and reward-related learning in the human brain: Insights from neuroimaging. Curr. Opin. Neurobiol. 14: 769-776.

Packard, M.G. and Knowlton, B.J. 2002. Learning and memory functions of the basal ganglia. Annu. Rev. Neurosci. 25: 563-593. 
Paxinos, G. and Watson, C. 1998. The rat brain in stereotaxic coordinates. Academic Press, San Diego, CA.

Pisani, A., Gubellini, P., Bonsi, P., Conquet, F., Picconi, B., Centonze, D., Bernardi, G., and Calabresi, P. 2001. Metabotropic glutamate receptor 5 mediates the potentiation of $N$-methyl-D-aspartate responses in medium spiny striatal neurons. Neuroscience 106: $579-587$.

Puttemans, V., Wenderoth, N., and Swinnen, S.P. 2005. Changes in brain activation during the acquisition of a multifrequency bimanual coordination task: From the cognitive stage to advanced levels of automaticity. J. Neurosci. 25: 4270-4278.

Raichle, M.E., Fiez, J.A., Videen, T.O., MacLeod, A.M., Pardo, J.V., Fox, P.T., and Petersen, S.E. 1994. Practice-related changes in human brain functional anatomy during nonmotor learning. Cereb. Cortex 4: $8-26$.

Salamone, J.D., Wisniecki, A., Carlson, B.B., and Correa, M. 2001. Nucleus accumbens dopamine depletions make animals highly sensitive to high fixed ratio requirements but do not impair primary food reinforcement. Neuroscience 105: 863-870.

Schiltz, C.A., Kelley, A.E., and Landry, C.F. 2005. Contextual cues associated with nicotine administration increase arc mRNA expression in corticolimbic areas of the rat brain. Eur. J. Neurosci. 21: $1703-1711$.

Schoenbaum, G. and Roesch, M. 2005. Orbitofrontal cortex, associative learning, and expectancies. Neuron 47: 633-636.

Schroeder, B.E., Binzak, J.M., and Kelley, A.E. 2001. A common profile of prefrontal cortical activation following exposure to nicotine- or chocolate-associated contextual cues. Neuroscience 105: 535-545.

Schroeder, B.E., Schiltz, C.A., and Kelley, A.E. 2003. Neural activation profile elicited by cues associated with the anxiogenic drug yohimbine differs from that observed for reward-paired cues. Neuropsychopharmacology 28: 14-21.
Smith-Roe, S.L. and Kelley, A.E. 2000. Coincident activation of NMDA and dopamine D1 receptors within the nucleus accumbens core is required for appetitive instrumental learning. J. Neurosci. 20: $7737-7742$.

Swanson, C.J., Baker, D.A., Carson, D., Worley, P.F., and Kalivas, P.W. 2001. Repeated cocaine administration attenuates group I metabotropic glutamate receptor-mediated glutamate release and behavioral activation: A potential role for Homer. J. Neurosci. 21: 9043-9052.

Teather, L.A., Packard, M.G., Smith, D.E., Ellis-Behnke, R.G., and Bazan, N.G. 2005. Differential induction of c-Jun and Fos-like proteins in rat hippocampus and dorsal striatum after training in two water maze tasks. Neurobiol. Learn. Mem. 84: 75-84.

Thomas, K.L., Arroyo, M., and Everitt, B.J. 2003. Induction of the learning and plasticity-associated gene Zif268 following exposure to a discrete cocaine-associated stimulus. Eur. J. Neurosci. 17: $1964-1972$.

Ungerleider, L.G., Doyon, J., and Karni, A. 2002. Imaging brain plasticity during motor skill learning. Neurobiol. Learn. Mem. 78: $553-564$.

White, N.M. 1997. Mnemonic functions of the basal ganglia. Curr. Opin. Neurobiol. 7: 164-169.

Xiao, B., Tu, J.C., Petralia, R.S., Yuan, J.P., Doan, A., Breder, C.D., Ruggiero, A., Lanahan, A.A., Wenthold, R.J., and Worley, P.F. 1998. Homer regulates the association of group 1 metabotropic glutamate receptors with multivalent complexes of homer-related, synaptic proteins. Neuron 21: 707-716.

Received May 29, 2006; accepted in revised form July 6, 2006.
608 Learning \& Memory

www.learnmem.org 


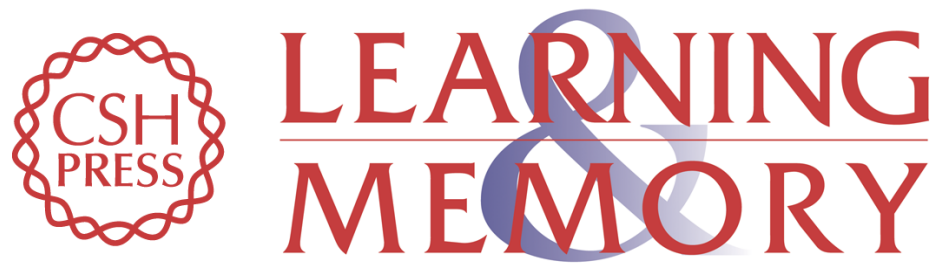

\section{Dynamic shifts in corticostriatal expression patterns of the immediate early genes Homer $1 a$ and Zif268 during early and late phases of instrumental training}

Pepe J. Hernandez, Craig A. Schiltz and Ann E. Kelley

Learn. Mem. 2006, 13:

Access the most recent version at doi:10.1101//m.335006

Related Content Dynamic neuroplasticity and the automation of motivated behavior

Brandon J. Aragona and Regina M. Carelli

Learn. Mem. UNKNOWN , 2006 13: 558-559

References This article cites 55 articles, 15 of which can be accessed free at:

http://learnmem.cshlp.org/content/13/5/599.full.html\#ref-list-1

Articles cited in:

http://learnmem.cshlp.org/content/13/5/599.full.htmI\#related-urls

License

Email Alerting Receive free email alerts when new articles cite this article - sign up in the box at the Service top right corner of the article or click here. 